\title{
An Overview of the Technological Progress in Propellants Using Hydroxyl-Terminated Polybutadiene as Binder During 2002-2012
}

\author{
Simone Carvalho Rufino, Gilson da Silva', Koshun Iha²
}

\begin{abstract}
The purpose of this article is to present a study on the technological development of propellants, which are used in solid and hybrid rocket motor, that have been employing hydroxyl-terminated polybutadiene (HTPB) as a binder, for the past ten years. The results prove that major research conducted on propulsion technologies continues using HTPB as a binder, with China and the United States being the countries with greater publications, and Brazil appearing at the fifth position in the ranking. The scientific and technological information was collected from articles, conference papers, reviews (over the last ten years) and patents granted in the United States by scientific and USPTO patent databases.
\end{abstract}

KEYWORDS: Propellant, Hydroxyl-terminated polybutadiene (HTPB), Patent, Article, Conference paper, Review.

\section{INTRODUCTION}

This article presents a review on the technological development behavior of hydroxyl-terminated polybutadiene (HTPB)-based propellants used in solid and hybrid rocket motor during the last decade, using scientific and technological information collected from articles, conference papers, reviews and patents granted by the US patent and trademark office (USPTO) database.

Companies and research institutions have been increasingly dedicated to technological forecasting as a tool for technology monitoring, investigation of new fields of investment and for minimizing the risks involved in research projects. The management of information and knowledge, in addition to excluding the subjectivity of decisions, provides technical support (Ortiz et al., 2002). They are looking for trend indicators such as the characteristics of scientific and technological production (year, country), key players involved in the market (competitors and/or potential partners), maturity of technology, development patterns, and correlated technologies, among others, which often indicate the length of active and emerging technologies.

Papers are responsible for the dissemination of scientific research, and their results corroborate existing studies and inspiration for further research. Patents, in turn, are excellent indicators of innovation, as they represent the industrial application of the results of research and development; in other words, the ability of a country to transform scientific knowledge into technological product or results.

\footnotetext{
1.Instituto Nacional da Propriedade Industrial - Rio de Janeiro/RJ - Brazil 2.Instituto Tecnológico de Aeronáutica - São José dos Campos/SP - Brazil Author for correspondence: Gilson da Silva | Instituto Nacional da Propriedade Industrial | Praça Mauá, 7 - Centro | CEP 20.081 -240 Rio de Janeiro/RJ Brazil | Email: gilsondasilva@uol.com.br Received: 19/03/13 | Accepted:17/05/13
} 
In the particular case of patents, they may not represent the real technological scenario, as, in general, these documents are considered strategic information for the country and the applicant chooses to make the patent application in secrecy, as it is in Brazil, and nobody can read the contents of this application (LPI no 9279/96, cap. IX) (PN no 1888/MD). For these reasons, the results in this article represent only the patents that are available to society from the United States (USPTO). Particularly, the choice by the U. S. patent database is due to the policy adopted by the United States to replace the shuttles used until then.

Another important aspect that should be considered in the search for technological information, is that scientific documents represent more current information, once the publication of research in journals and congress occurs immediately. On the other hand, a usual patent is kept in secret for 18 months, except when an applicant requires an anticipated publish date.

\section{PROPELLANTS}

Propellants are chemical compounds (normally, homogeneous) or mixtures (normally heterogeneous) that on ignition, exhibit self-sustained combustion and generate large volumes of hot gases at controlled, predetermined rates (Miskelly, 2004). The specific chemical composition depends on the desired combustion characteristics for a particular application (Beckstead et al., 2007), and propellants can be tailored so as to achieve desired burning rate characteristics (Miskelly, 2004). The main selection parameters are the specific impulse (Isp), the thrust, the flight speed, the simplicity of the technology, the storage ability, the safety and the reliability (Gascoin et al., 2012), and low pollutants in combustion.

Propellants serve as a convenient, compact form of storing relatively large amounts of energy and working fluid for rapid release and enjoy wide utility in various industrial and military applications. Thus, propellants are generally employed in various situations requiring a readily controllable source of energy such as ballistic applications (e.g., for periods of time ranging from milliseconds in weapons to minutes for space vehicles) in which the generated gases function as a working fluid for propelling projectiles, for example rockets and missile systems, and also for pressurizing pistons and inflating containers (Miskelly, 2004).
Propellants can be divided basically into three groups: solid, in which all components used in the formulation are solid; hybrid, which usually has a solid fuel and a liquid or gas oxidizer; and liquid, which is characterized in that the fuel and oxidant are liquid, typically stored in separate reservoirs, and only react when mixed together inside the combustion chamber (Paterlini et al., 2002). In cases where the HTPB is the most common binder for solid and hybrid propellants, the results of this article will not involve liquid propulsion.

\section{SOLID PROPELLANTS}

A solid rocket motor (SRM) or a composite propellant rocket motor is a rocket with a motor that uses solid propellants comprising a fuel and an oxidizer. The solid propellant is usually in the form of a propellant grain placed within the interior of the rocket motor (e.g. in the combustion chamber) and burned to produce hot gases, which, in turn, exit through the throat and nozzle of the rocket motor at a high velocity to provide a thrust that propels the rocket in the opposite direction (Petersen et al., 2012). It is widely used in tactical and strategic missiles (Rao et al., 2004) and considering the condition in which its constituent ingredients are interconnected, can be classified as homogeneous and heterogeneous (Beckstead et al., 2007).

In a homogeneous propellant, the ingredients are linked chemically and the resulting physical structure is homogeneous throughout. Typical examples of homogeneous propellants are single-base (NC- nitrocellulose) or double-base (NC and NGnitroglycerine) propellants (Beckstead et al., 2007).

In heterogeneous or composite propellants, theingredients are physically mixed, resulting in a heterogeneous physical structure (Beckstead et al., 2007). These energetic materials are made by embedding finely divided crystalline oxidizer particles, such as ammonium perchlorate (AP), in a resinous or elastomeric matrix, based on HTPB, called a "binder". The binder usually provides the fuel for the combustion reaction, although solid-reducing agents, such as aluminum (Al), are frequently included in the compositions (La Fuente, 2009). Rocket propellant formulations based on AP/Al/HTPB are extensively used, as they enable high performances to be achieved with a high specific gravimetric or specific impulse (Isp) and volumetric impulse (Ispv) (Bohn and Cerri, 2010).

Formulations of solid propellants also contain other chemical ingredients such as ballistic modifiers, bonding agents, plasticizers, curing agents, stabilizers and crosslinking agents (Beckstead et al., 2007). 


\section{HYBRID PROPELLANTS}

Hybrid propulsion is a promising technology, as it is safer, can have a higher average specific impulse, and is environmental friendly. Hybrid propellants can be easier throttled and restarted than solid propellants and are less expensive and complex than liquid propellants in terms of development and management of the propulsive system (Guobiao et al., 2011; Gomes, 2012).

A typical hybrid rocket motor (HRM) uses a liquid oxidizer and a solid fuel propellant. The motor structure consists of a liquid oxidizer storage, a feed system and a solid fuel thrust chamber (Guobiao et al., 2011). This technology involves the burning of the solid fuel contained in the combustion chamber with the injected oxidizer, either liquid or gaseous (heterogeneous combustion). The separation of the propellant components produces a very safe engine and by controlling the injection via a regulation valve, it is possible to adjust the thrust, to shut the engine down and to reignite it later if necessary (Gascoin et al., 2012).

The choice of the oxidizer is more limited, as it should be non toxic, safe, and present a high burning rate. The three most frequently used oxidizers are oxygen (liquid LOx or gas $\mathrm{GOx})$, hydrogen peroxide $\left(\mathrm{H}_{2} \mathrm{O}_{2}\right)$, and nitrous oxide $\left(\mathrm{N}_{2} \mathrm{O}\right)$ (Gascoin et al., 2012). Limitations are still faced with regard to solid fuel, such as low regression rate and combustion inefficiency, causing unproven capability of large rocket operations. HTPB is also largely studied, because it is one of the most frequently used in solid propulsion but while offering good mechanical properties, it presents low regression rates. A recommended strategy for HTPB-based solid fuels is to increase regression rates by fluid dynamics means (swirling flows); high-energy metallic additives can be used to sensibly increase density and specific impulse while contrasting nozzle erosion and further augmenting regression rates (DeLuca et al., 2013). The addition of metal particles (Al, $\mathrm{Li}, \mathrm{Mg}$ and $\mathrm{B}$ ) as well as metal hydrides $\left(\mathrm{AlH}_{3}\right.$ and others) is investigated as a means of increasing their combustive and thermomechanical properties (notable increase of regression rate), such as the flame temperature and the density (Gascoin et al., 2012).

Different from SRM, the solid fuel regression rate in HRM is predominantly driven not by the chamber pressure but by the oxidizer mass flow rate. At a constant oxidizer mass flow rate for a simple cylindrical-grain motor, the thrust value descends with time into the firing, as the grain port diameter (equivalent diameter if not a circle port) and area increase, thus reducing the mass flux- dependent fuel regression rate. The thrust affects the flight trajectory directly. Therefore, the optimal design of an HRM might be better established if undertaken in the context of meeting a rocket vehicle's particular mission requirements (Guobiao et al., 2011).

Studies show that the high-concentration $\mathrm{H}_{2} \mathrm{O}_{2}$ exhibits greater performance than $\mathrm{N}_{2} \mathrm{O}$ and is easier to handle than liquid oxygen in HRMs. The application of $\mathrm{H}_{2} \mathrm{O}_{2}$ /HTPB propellant combination in the research field of HRM is becoming popular with the development of $\mathrm{H}_{2} \mathrm{O}_{2}$ concentration and handling technology. There are two standard concentrations for high concentration $\mathrm{H}_{2} \mathrm{O}_{2}: 98$ and $90 \%$. Besides the initial grain shape parameters, the HRM and rocket vehicle's performance are determined by four initial design parameter values, including initial thrust, chamber pressure, mixture ratio and nozzle expansion ratio (Guobiao et al., 2011).

\section{GREEN PROPELLANTS}

The great problem faced by most of the currently used solid rocket fuels is that they are still based on mixtures of AP, aluminum (Al) and resins, which produces hydrochloric acid $(\mathrm{HCl})$ and aluminum oxides during combustion. Therefore, AP-based propellant formulations are not considered green propellants. The quest for more energetic propellants with reduced pollutant emissions has resulted in the use of several non-AP ingredients in solid propellants. The ingredients belong to a wide spectrum of chemical families, but mostly fall into one of the following four categories:

- Nitramines: cyclotrimethylenetrinitramine (RDX), cyclotetramethylenetetranitramine (HMX), the known as CL-20; hexanitrohexaazaisowurtzitane (HNIW), hydrazinium nitroformate (HNF)

- Azides: glycidyl azide polymer(GAP), 3,3'-bis (azidomethyl) oxetane (BAMO), 3-azidomethyl-3-methyloxetane (AMMO)

- nitrate esters: NG, NC, 1,2,4-butane triol trinitrate (BTTN), metriol trinitrate (TMETN), diethylene glycol dinitrate (DEGDN)

- Nitrates: ammonium dinitramide (ADN), ammonium nitrate (AN) (Beckstead, 2007; Badgujar et al., 2008).

Cyclic nitramines such as RDX and HMX have received significant attention as energetic components of modern eco-friendly propellants by virtue of their positive heat of formation (+58.5 and $+75 \mathrm{~kJ} / \mathrm{mol}$, respectively), superior 
chemical and thermal stability, as well as the presence of reduced pollutants in combustion products and non-smoky exhaust similar to that of double-based propellants. Since RDX and HMX contain a high concentration of hydrogen atoms, the combustion of nitramine produces lowmolecular-weight gases. Therefore, they produce relatively high specific impulses even though the adiabatic flame temperature is low. Furthermore, the combustion products are not only smokeless but also noncorrosive (Naya and Kohga, 2013). The use of HNF has also received attention due to its benefit in terms of clean combustion and superior heat of formation $(-71 \mathrm{~kJ} / \mathrm{mol})$ in relation to AP oxidizer (Badgujar et al., 2008).

In addition, the use of energetic azides, mainly GAP, in propellant formulations reduces the amount of flame and smoke in the exhaust gases, thus making the propellant formulations more eco-friendly (Badgujar et al., 2008).

The use of $\mathrm{ADN}$ instead of ammonium perchlorate certainly increases the energy of the propellant formulation and the burning rate of propellants. $\mathrm{ADN}$ exhibits superior heat of formation $(-151 \mathrm{~kJ} / \mathrm{mol})$ and is prepared from aliphatic monoisocyanate using stoichiometric quantities of nitronium tetrafluoborate and nitric acid in acetonitrile as the nitrating medium followed by ammonia treatment. The $\mathrm{NH}_{4}^{+}$or $\mathrm{K}^{+}$salts of dinitramide are more stable compared with dinitramines. So, ADN combines the low sensitivity of ammonium salts with the high burning rates of nitramines. It has a low melting point, is slightly hygroscopic, and, hence, needs special process conditions (Badgujar et al., 2008).

\section{METHODOLOGY}

Articles, conference papers, and reviews used in the present work were recovered using Scopus, Science Direct and Web of Science databases, which are the usual databases in a scientific community. Patents were recovered from the USPTO Patent Full Text and Image Database (PatFT). The choice of the USPTO database was based on the economic potential of the market in the United States, already recognized worldwide and supported by a large number of scientific publications in the area of interest of this study. In addition, this database is the one that allows free access to the search, specifically in the claims. In the case of patent documents, this field describes the matter to be protected or the invention itself, and is, therefore, the field in which one should seek topics of interest.

The search was done considering documents in which both keywords "propellant or propellants" and "polybutadiene or HTPB", are present in the title, abstract, or keywords, in the Scopus database. In the Science Direct database, the search was done considering documents in which one of the words "htpb" or "polybutadiene" were present in the title, abstract or keywords and the word "propellant" was present in the whole text. The search in the Web of Science database was done considering documents in which one of the words "htpb" or "polybutadiene" were present in the title and the word "propellant" was present in the whole text.

Document publication date was limited to the range from January 1, 2002 to December 31, 2012.

Documents recovered, from reading the abstracts, were selected while excluding overlaps and considering only the ones related to studies on SRM and hybrid rocket motor (HRM), which used HTPB as a binder and investigated the properties of the propellant.

The results were compiled in terms of number of documents, document type (article, conference paper and review), assignee countries, affiliation (universities and research institutes) and the main subjects or properties studied in these documents, considering the title and the abstract.

The following documents recovered by this search strategy were excluded: those in which the compositions in which HTPB was blended with a single-base propellant were described; those in which ignition models and ignition delay were described; and those in which the compositions in which HTPB was used in waterjet motors were described.

\section{RESULTS AND DISCUSSION}

From the search, 346 relevant documents were recovered and from that, 30 publications are related to green propellants (considering compositions that do not use AP as an oxidizer). The search also showed 30 publications that investigate the use of HTPB as a binder in hybrid propellants and these will be discussed later.

Figure 1 presents the number of documents from 2002 to 2012 as well as their type (article, conference paper or review). Figure 1 shows a continuous growth rate of publications, 


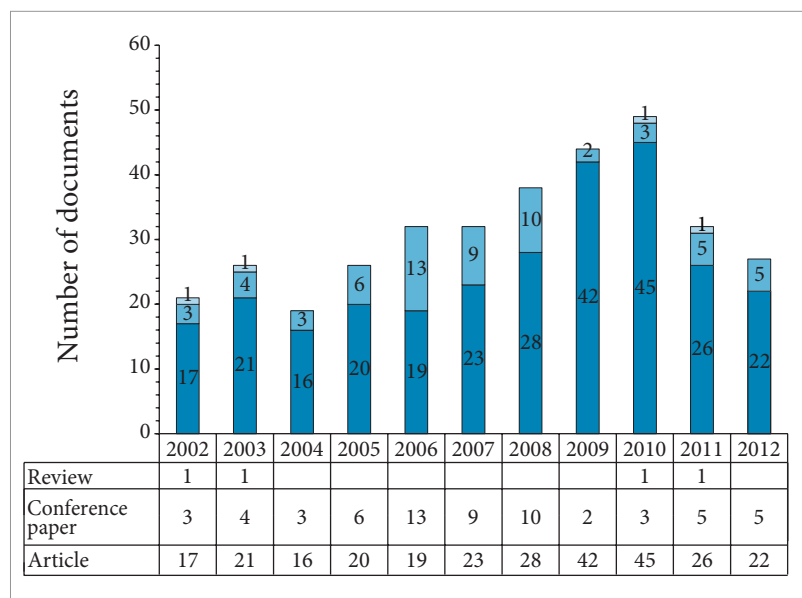

Figure 1. Number of documents, specifying each kind, that describe the use of HTPB as binder over the years from 2002 to 2012 .

which is observed until 2010, followed by an expressive reduction in scientific publication between 2011 and 2012.

Considering the type of documents, 279 were articles, 63 were conference papers and only 4 were reviews. As one can see, once the contribution toward the particular research area was provided by articles, the rate of decrease of the publications observed in the years 2011 and 2012 (Fig. 1) was directly related to the specific kind of document.

One point that should be observed is that almost $44 \%$ of all scientific production focuses on the last four years of the period studied, which can suggest an increase in interest in that scientific research branch.

Considering the affiliation of the research (Fig. 2), results showed that research institutes, which comprise private research institutes and government agencies, were responsible for about $50 \%$ of the publications made (142, in total period). The total number of publications made only by the universities $(105$, in total period) and the total number of publications that were the result of a partnership between the university and research institutes (99, in total period) are very similar, from which it is possible to observe that both units, responsible for that area of research in a country, although they were able to develop scientific research in this area alone, were open to working together.

Considering the assignee countries, were selected from the results obtained the 5 countries that presented the most publications. Figure 3 shows that China occupies the first position, which corresponds to 172 publications in the last 10 years, followed by the United States which has 56, with less than half of the publications of China. India, Japan and Brazil

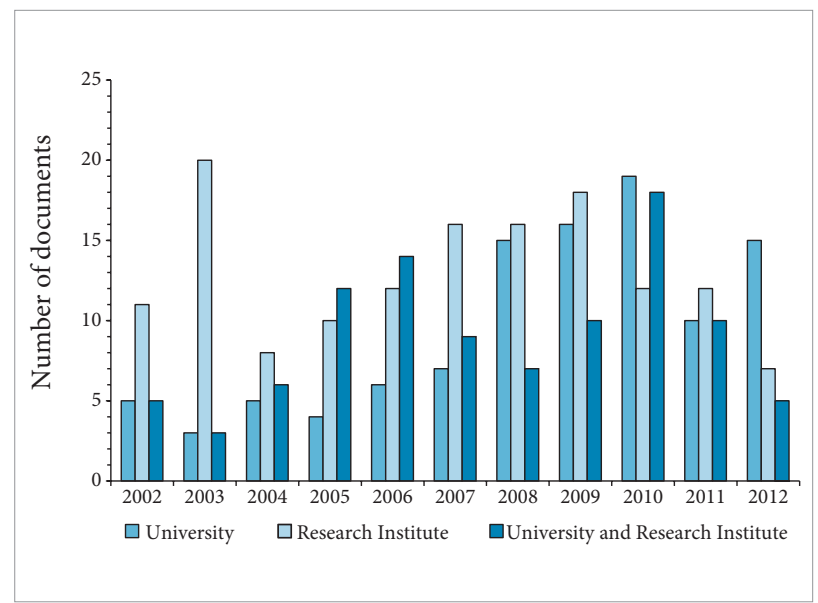

Figure 2. Number of documents of each affiliation and the kind of research institution from 2002 to 2012.

have, respectively, 34, 25, and 10 publications in this period. These results indicate the Chinese government's effort toward the development of this technology that is most widely used in the area of propellants in agreement with the Chinese aerospace program. The United States occupies the second position, suggesting that investments are still done in this kind of propellant in order to improve properties, such as burning rate and flame structure. Brazil occupies a good position (fifth), showing the return on investments made in training developed in research institutes and universities. It might be observed, from Fig. 3, that there was an investment increase in propellant research in China, from 2002 to 2012.

Considering the abstracts, publications were selected by the subject relevance and were grouped while considering the compositions and the properties investigated. In Figs. 4 and 5,

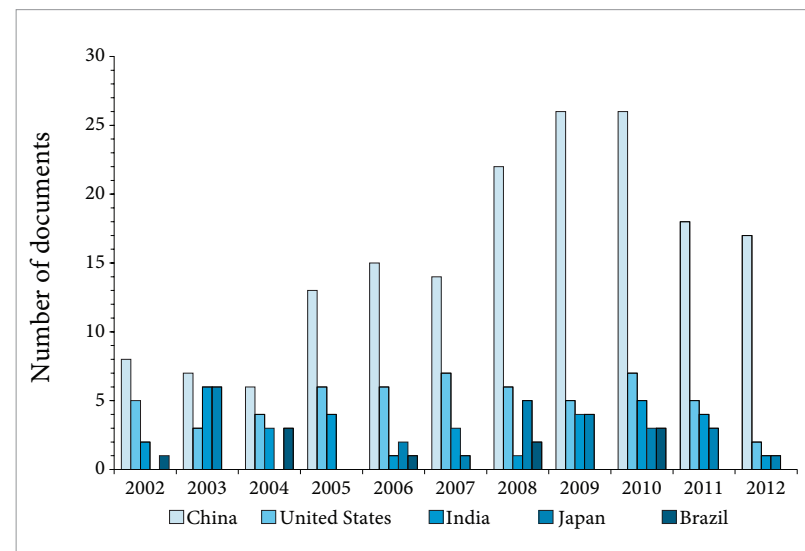

Figure 3. Number of documents of each assignee country from 2002 to 2012 . 
"metal" represents aluminum and boron, and "energetic material" represents the explosives RDX, HMX, HNF, CL20, ONC, ADN, DNTF, TNAZ, and DNOAF. Figures 4 and 5, respectively, show the results considering the propellant compositions and the properties, investigated, during the whole period (2002-2012).

In several publications (104, in total period), results showed that the other components used with HTPB in propellant composition were not specified in abstracts, and it was only described that this composition had these components. However, it is apparent that there has been a large investment in research on the properties of compositions with ammonium perchlorate, as oxidant, and HTPB, as binder (112, in total period). The combination of metal (Al or $\mathrm{B})$ and $\mathrm{AP}$ to enhance properties in propellant

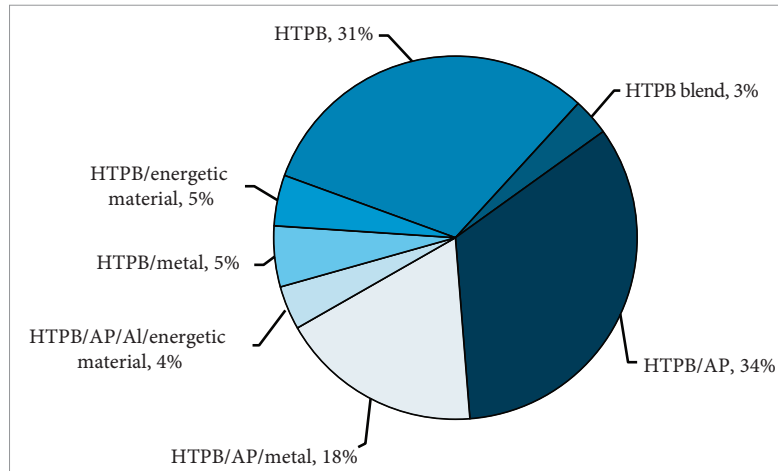

HTPB: hydroxyl-terminated polybutadiene; AP: ammonium perchlorate Al: aluminum

Figure 4. Percentage distribution of documents of the most relevant propellant compositions from 2002 to 2012.

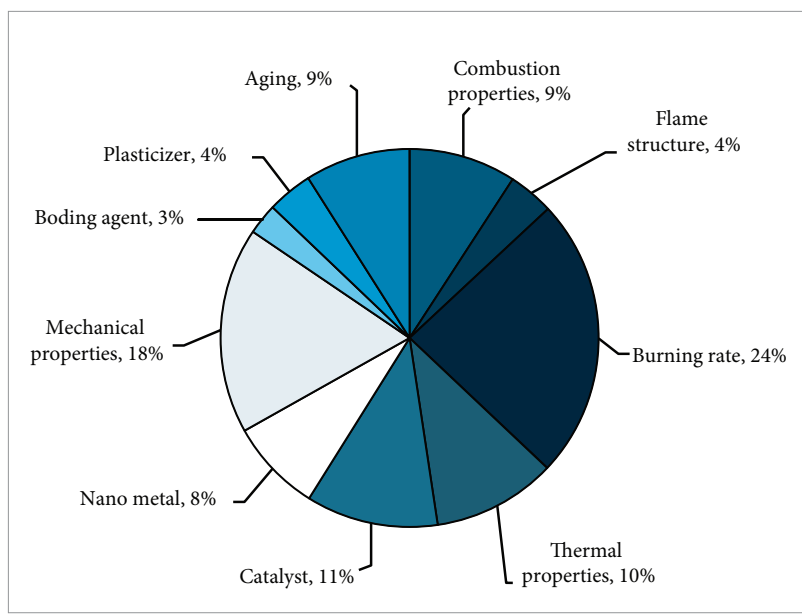

Figure 5. Percentage distribution of documents of the most relevant properties investigated from 2002 to 2012. compositions represented approximately half of the studies done with AP/HTPB (60, in total period).

With regarding to the properties investigated, results showed that the research was focused on the search for compositions with an improved burning rate (136, in total period) and better mechanical properties (100, in total period). Studies on the effect of the catalyst used in composition (64, in total period) and on the use of nano metals in the compositions (45, in total period) were also important. Studies on the effect of aging on composition properties were also representative (51, in total period), followed by the combustion properties (52, in total period) and also the thermal properties (60, in total period).

Figures 6 and 7, respectively, consider the behavior of the focus of research over theyears 2002-2012. Results showed that, in 2006, the studies on compositions HTPB/AP/Metal had an expressive increase, but the attention on these compositions decreased in 2008, when there was an unexpected increase in studies on compositions of $\mathrm{HTPB} / \mathrm{AP}$ without metal. Even during 2009-2012, the research on HTPB/AP remained preferable in relation to $\mathrm{HTPB} / \mathrm{AP} /$ metal, accompanied by the interest in the mechanical properties of these compositions, which were directly related to the energy and the performance of the propellant, as seen in Fig. 7.

\section{GREEN PROPELLANT COMPOSITIONS}

Based on results, 30 publications could be called "green propellant compositions". Here, those compositions that do

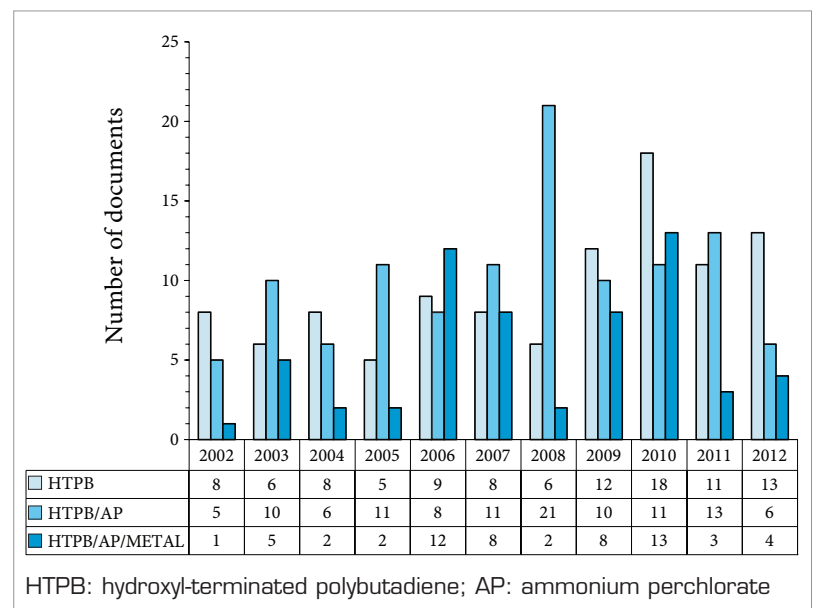

Figure 6. Distribution of documents of the most relevant propellant compositions from 2002 to 2012. 


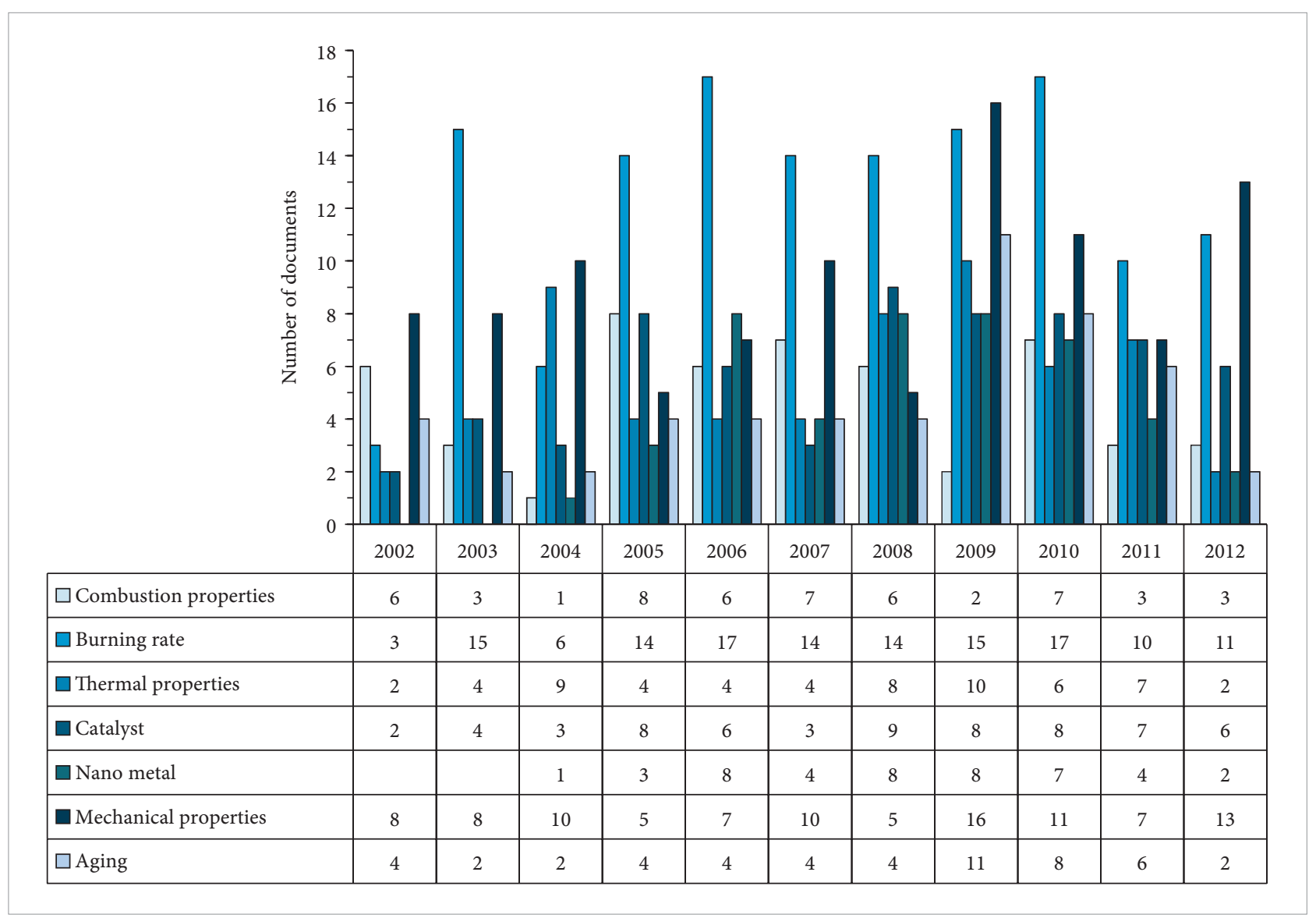

Figure 7. Distribution of documents of the most relevant properties investigated from 2002 to 2012.

not use AP as an oxidizer will be considered green propellant compositions; in other words, compositions employing nitrate ammonium as an oxidizer, $\mathrm{Al}$ or $\mathrm{B}$ as a metal, and explosives RDX, HMX, HNF, CL20, ONC, ADN, DNTF, TNAZ, GAP, and DNOAF as "energetic material". Figure 8 shows the number of documents related to green propellant compositions from 2002 to 2012.

The small number of green publications in relation to the total number of publications (346) indicates that, despite there being some worries in searching for nonpolluting technologies, this effect is still not significant in propellants, which can also indicate the level of difficulty in finding a suitable replacement for HTPB, in view of its characteristics (stability and/or compatibility with the other components in the propellant's composition). However, from 2007, an increase was observed in research related to this matter, indicating a greater environmental awareness. Thus, the total number of green publications, from 2007 to 2012, reached a level of approximately $9 \%$ of the total publications over the same period.

Another point to be observed is that most of the publications in this area were proceeding from research institutes, with 15 publications. The universities showed a modest number of publications, with only 5 works reported. However, partnerships between research institutes and universities were stimulated, showing ten publications in the entire period. Most of the publications were articles (24, in total period) followed by conference papers $(5$, in total period) and only one was a review.

Again, China was the most expressive assignee country with 14 publications in the entire period, which represents more than four times than each one of the other countries. China was followed by the United States, India, and Japan, each of which had three publications. 
On the other hand, the fact that Brazil does not provide publications in the area of green propellants can indicate a simple lack of interest in this subject or a technological backwardness in relation to other countries, which would already be working on improving composition propellants in replacement of toxic and/or harmful to environment.

Figure 9 shows the number of documents related to the most prominent assignee countries from 2002 to 2012. Results showed that the only country which had maintained its research on regular basis was China. Recently (2010 and 2011, respectively), India and Japan also reported their research, but the United States, since 2007, has not reported publications involving this kind of propellants.

Figure 10 shows that studies conducted on HTPB/ energetic material compositions were the most expressive in the entire period, as they involve many different kinds

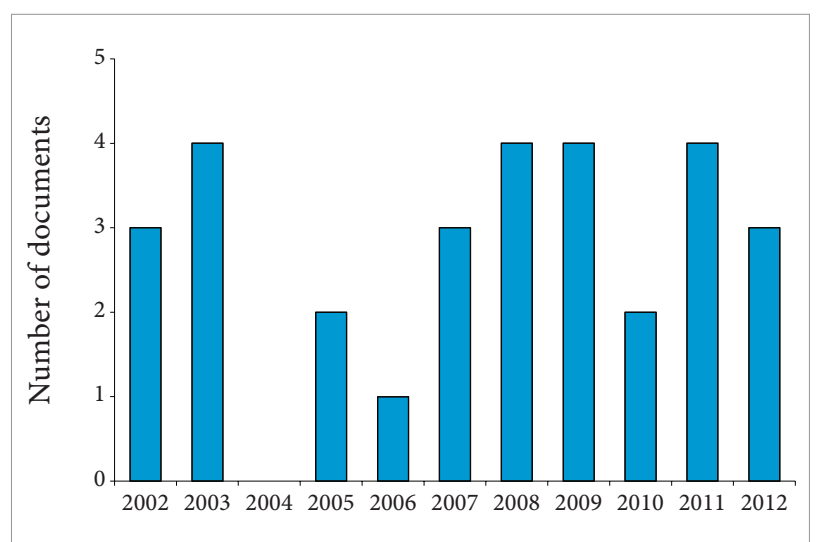

Figure 8. Number of documents about green propellants from 2002 to 2012.

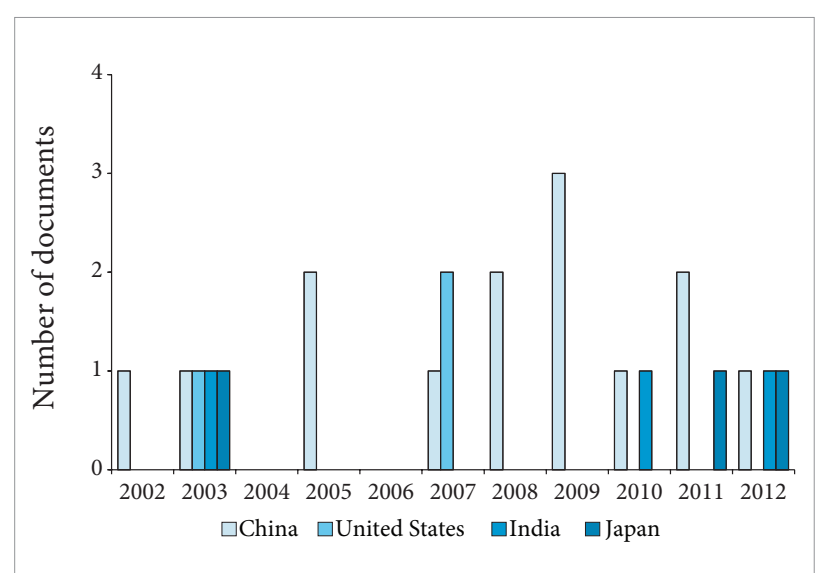

Figure 9. Number of documents of each assignee country from 2002 to 2012 . of explosives as oxidizers. When analyzed in isolation, each composition represents less than three publications in the entire period. For this reason, what can be seen from this figure is that $\mathrm{HTPB} / \mathrm{AN}$ was the most important composition with eight publications. Similar behavior can be observed from 2008 until 2011, where there was an increase in research involving energetic materials as oxidizers.

The combination of metal and HTPB/AN did not have an expressive representation, as it had only two publications, one with $\mathrm{Al}$ as metal and another with $\mathrm{B}$, and, indeed, since 2006, there has been no publication in this area.

The major property studied in publications was the burning rate, as observed in traditional compositions (Fig. 11), corresponding to $31 \%$ of all publications.

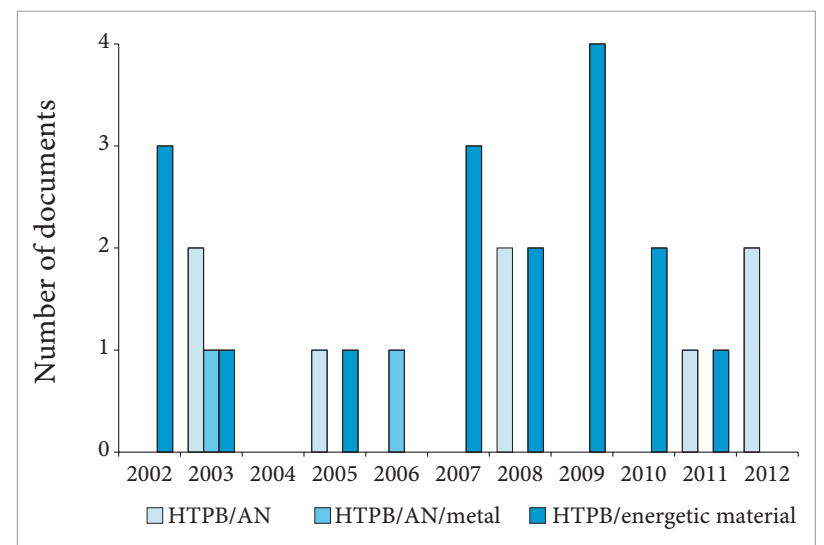

Figure 10. Number of documents of most relevant propellant compositions from 2002 to 2012.

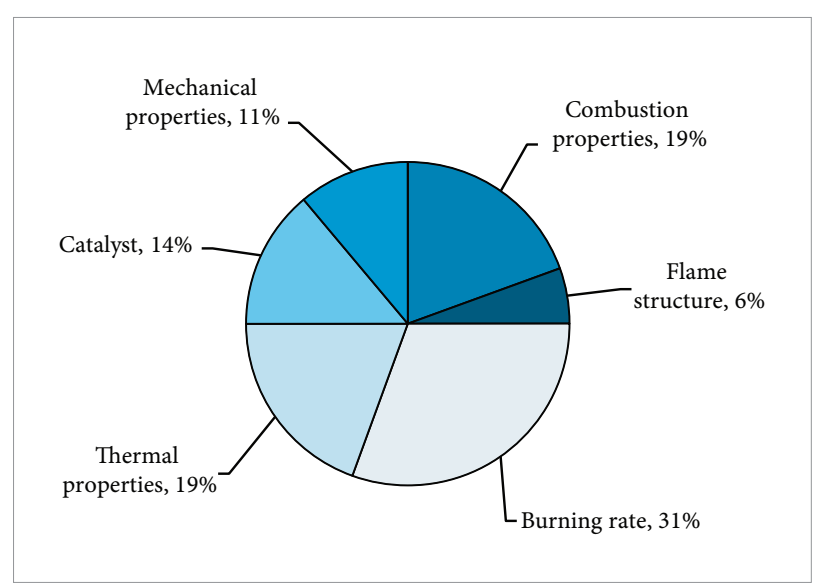

Figure 11. Percentage distribution of documents of most relevant properties, for green propellants, investigated from 2002 to 2012 . 


\section{HYBRID PROPELLANT COMPOSITIONS}

Based on the search, 30 publications that investigate the use of HTPB as a binder system in a hybrid propellant were recovered. Figure 12 shows an increase in this research area with a great difference in 2008. In 2009, the number of publications started falling and then, resumed increasing in 2012.

Results showed that the number of publications, as articles, were 17 , in the entire period, and they were very similar to those such as conference papers, which were 13 publications. This might suggest the interest in promoting the dissemination of this technology in congress and technological events. It can also be concluded that major research was conducted by the universities (15 documents, in the total period), which may corroborate the high number of publications in the congress. The number of publications from research institutes was six, which was very similar to those published in association with the university ( 9 , in the total period). These results may indicate the good relations between research units.

The major assignee countries were China (11, in the total period), the United States (10, in the total period), and Italy (3, in the total period), and this may indicate that China was searching for research in traditional areas, such as solid propellants. Indeed, China had also been making investments in new or alternative technologies in propulsion areas. As can be seen in Fig. 13, the United States had been studying these propellant compositions since 2002 and China started reporting its scientific results in this area only in 2005. In 2009, the United States decreased its investment and until 2010, it did not have publications in this area. In 2012, only China showed interest in studying this kind of compositions.

Figure 14 presents the percentage distribution of the number of publications that investigated the major hybrid propellant compositions, which were $\mathrm{HTPB} / \mathrm{N}_{2} \mathrm{O}, \mathrm{HTPB} /$ $\mathrm{H}_{2} \mathrm{O}_{2}, \mathrm{HTPB} / \mathrm{LOx}, \mathrm{HTPB} / \mathrm{GOx}$, and HTPB/GOx/AP/Fe $\mathrm{O}_{3}$.

It shows that $\mathrm{HTPB} / \mathrm{N}_{2} \mathrm{O}, \mathrm{HTPB} / \mathrm{H}_{2} \mathrm{O}_{2}$, and $\mathrm{HTPB} / \mathrm{LOx}$ were the most frequently used compositions reported in scientific publications, and also shows the technology evolution from 2002 to 2012 . One also can observe the recent interest in $\mathrm{HTPB} / \mathrm{H}_{2} \mathrm{O}_{2}$ propellants and that, in 2008, the system $\mathrm{HTPB} / \mathrm{N}_{2} \mathrm{O}$ was intensely investigated but after 2009 , there was no publication involving this system. Moreover, Fig. 14 shows that HTPB/LOx systems were investigated from 2003 to 2006 and then, they only returned to be reported in 2008 .
Figure 15 shows the percentage distribution of documents with the most relevant properties for hybrid propellants over the entire period. One can see that the property which was mostly investigated was the regression rate of the propellant, which was directly related to the performance of the propellant that occupies the second priority position, as with the improve energy of formulations may be obtained, as observed before.

Results revealed that the most relevant properties studied from 2009 to 2012 were the regression rates of compositions, followed by combustion properties and simulation studies. From 2003 to 2008, studies involving the performance of the system gained prominence followed by investigations about the regression rate of the systems.

Results showed that when the composition interest was changed from the use of $\mathrm{N}_{2} \mathrm{O}$ to the use of $\mathrm{H}_{2} \mathrm{O}_{2}$ (Fig. 14), the focus of the studied properties changed to

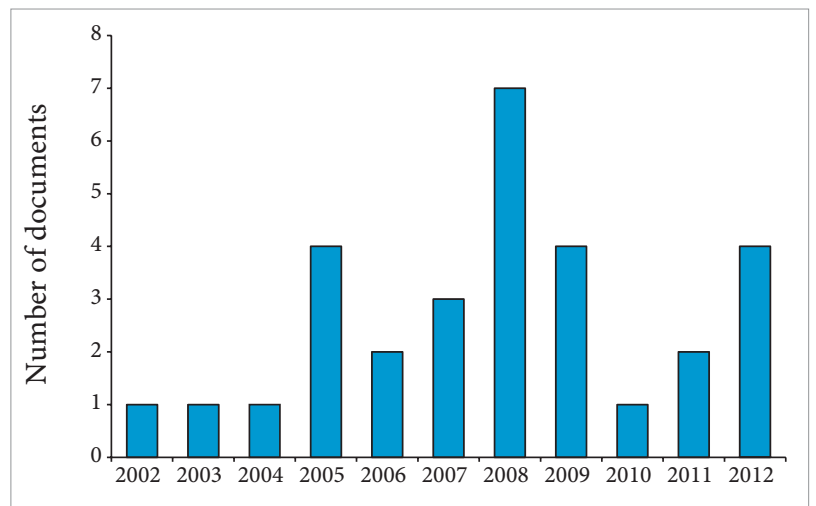

Figure 12. Number of documents about hybrid propellant compositions from 2002 to 2012.

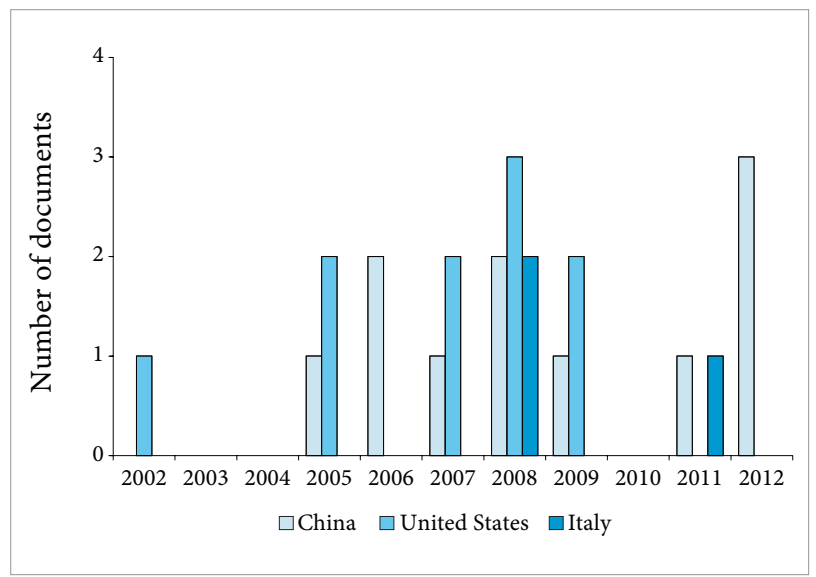

Figure 13. Number of documents of each assignee country from 2002 to 2012 . 


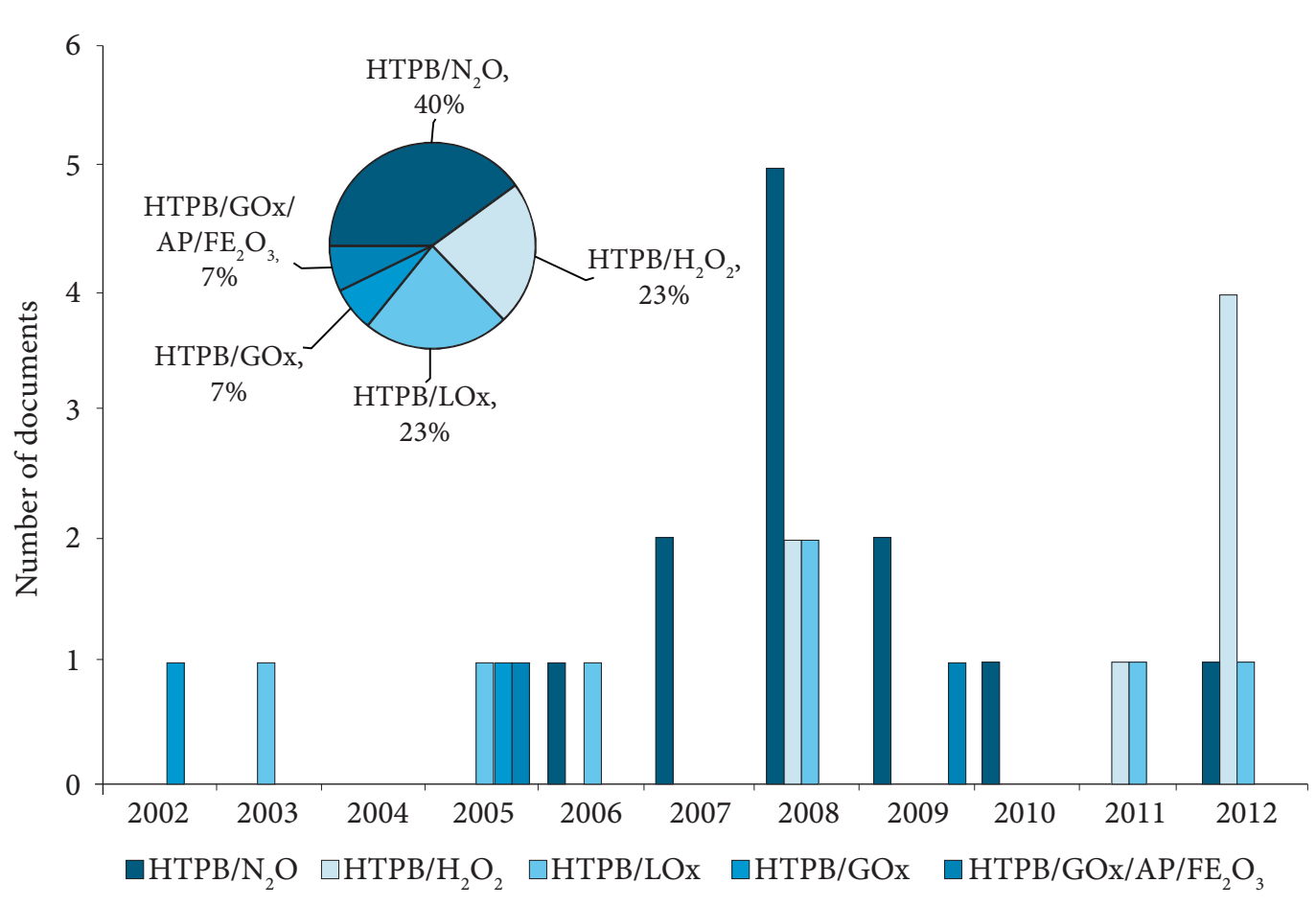

HTPB: hydroxyl-terminated polybutadiene; AP: ammonium perchlorate; LOx: liquid oxygen; GOx: gas oxygen

Figure 14. Number of most relevant documents of propellant compositions and their percentage distribution from 2002 to 2012.

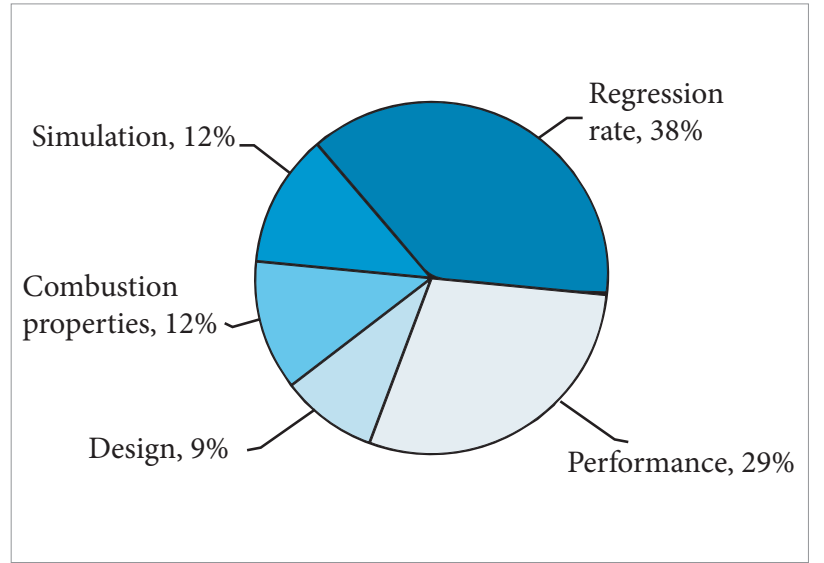

Figure 15. Percentage distribution of documents of the most relevant properties, for hybrid propellants, investigated from 2002 to 2012.

regression rate, which can be related to an improvement in the energy of the propellant achieved, instead of performance, which was the focus property studied in formulations using $\mathrm{N}_{2} \mathrm{O}$.

\section{PATENTS}

The database of the USPTO, as well as other patent offices in the world (Sipo - China, Paj - Japan, INPI - Brazil, etc.), has unrestricted public access. This research has focused only on the USPTO's database because of the American interest in changing its aerospace program, which until then was based on the use of shuttle. The patent documents were recovered using the USPTO Patent Full-Text and Image Database (PatFT). Only the documents in which the claims were present were considered: both words "propellant or propellants" and "polybutadiene or HTPB". In the searches, the date when the application was submitted to this patent office (application date) was limited from January 1, 2002 to December 31, 2012.

The recovered documents were filtered and considered only the ones related to studies on SRM and HRM, which used HTPB as a binder and investigated the properties of the propellant. 
Seven patent documents were recovered, which are compiled in Table 1. Almost all of them have the same International Patent Classification (IPC), C06B, that refers to "explosive or thermic compositions, manufactured thereof, use of single substances as explosives". These results could corroborate the search strategy efficiency.

In relation to the assignees, the results showed equilibrium between American universities and companies; the United States navy also has one patent open to the public.

The date when the patents were granted (granted dates) can be divided into two groups: 2005-2006 and 2010-2012. Recent patent topics show the market interest in solid propellants even nowadays, adjusting formulations in order to get and also improve properties, such as self-extinguishing and burning rate.

\section{FINAL CONSIDERATIONS}

Search results in the scientific publications databases showed that composite propellants which use HTPB as a binder are still one of the most used and investigated propulsion technologies. Private research institutes and government agencies are in charge of about $50 \%$ of the publications made in this area. China was the major country in relation to investments in research, followed by United States. Brazil also occupied a good position (fifth) showing the return on investment in training conducted by research institutes and universities.

Results also showed that studies on properties of compositions involving the use of AP as an oxidizer are still preferable, and major research is focused on investigating compositions which could have improved ballistic and mechanical properties. The use of catalysts and nano metals is also important in analyzing composition properties.

In publications involving green propellants, the use of $\mathrm{HTPB} / \mathrm{AN}$ represents the most important composition from 2008 until 2011, when an increase was observed in research involving energetic materials as an oxidizer in place of AN.

China is also the main country in relation to the number of publications in the hybrid propellants field, which may

Table 1. Patents documents describing the use of HTPB as binder in propellant compositions.

\begin{tabular}{|c|c|c|c|c|}
\hline Patent number & Title & Assignee & IPC (2006.01] & Granted date \\
\hline US8336287 & $\begin{array}{l}\text { Solid propellant rocket motor having self-ex- } \\
\text { tinguishing propellant grain and systems } \\
\text { therefrom }\end{array}$ & $\begin{array}{l}\text { University of Central } \\
\text { Florida Research } \\
\text { Foundation, Inc. }\end{array}$ & C06D5/00 & $\begin{array}{l}\text { December 5, } \\
2012\end{array}$ \\
\hline US8114229 & Self-extinguishable solid propellant & $\begin{array}{l}\text { University of Central } \\
\text { Florida Research } \\
\text { Foundation, Inc. }\end{array}$ & C06B29/00 & $\begin{array}{l}\text { February 14, } \\
\qquad 2012\end{array}$ \\
\hline US8066834 & $\begin{array}{l}\text { Burn rate sensitization of solid propellants } \\
\text { using a nano-titania additive }\end{array}$ & $\begin{array}{l}\text { University of Central } \\
\text { Florida Research } \\
\text { Foundation, Inc. }\end{array}$ & C06B29/22 & $\begin{array}{l}\text { November 9, } \\
2011\end{array}$ \\
\hline US7824511 & $\begin{array}{l}\text { Method of making GAP propellants by pre-re- } \\
\text { acting a metal fuel with isocyanate before } \\
\text { mixing with binder and plasticizer }\end{array}$ & US NAVY & C06B45/10 & $\begin{array}{l}\text { November 2, } \\
2010\end{array}$ \\
\hline US7011722 & Propellant formulation & $\begin{array}{l}\text { Alliant Techsystems } \\
\text { Inc. }\end{array}$ & C06B29/22 & $\begin{array}{l}\text { March 14, } \\
\quad 2006\end{array}$ \\
\hline US6913661 & $\begin{array}{l}\text { Ammonium nitrate propellants and methods } \\
\text { for preparing the same }\end{array}$ & $\begin{array}{l}\text { Universal Propulsion } \\
\text { Company, Inc }\end{array}$ & C06B31/28 & $\begin{array}{l}\text { July } 5 \\
2005\end{array}$ \\
\hline US6896751 & $\begin{array}{l}\text { Energetics binder of fluoroelastomer } \\
\text { or other latex }\end{array}$ & $\begin{array}{l}\text { Universal Propulsion } \\
\text { Company, Inc }\end{array}$ & C06B21/00 & $\begin{array}{l}\text { May 24, } \\
2005\end{array}$ \\
\hline
\end{tabular}

Fonte: USPTO Patent Full-Text and Image Database (PatFT). 
indicate that this country is not only looking for research in traditional areas, such as solid propellants, but also searching for new or alternative technologies in the propulsion area.

Based on the number of publications in this period, it is possible to infer that the area of research in propellants still appears young, and the research conducted in it, continues being promising.
The very low number of granted patent documents reported in open patent databases (USPTO), which uses HTPB in propellants as a binder could be associated with the legal aspects that are specific for each country, where, in some cases, this type of document may be considered of interest for national defense, not being published, and for this reason, preventing public consultation.

\section{REFERENCES}

Andrade, J., Iha, K., Rocco, J.A.F.F., Franco, G.P., Suzuki, N. and Suárez-lha, M.E.V., 2007, "Determinação dos parâmetros cinéticos de decomposição térmica para propelentes BS e BD”; Eclética química, Vol. 32, pp.45-50.

Beckstead, M.W., Puduppakkam, K., Thakre, P. and Yang, V. 2007, "Modeling of combustion and ignition of solid-propellant ingredients", Progress in Energy and Combustion Science, Vol. 33, pp. 497-551

Bohn, M.A. and Cerri, S., 2010, "Ageing behaviour of composite rocket propellant formulations investigated by DMA, SGA and GPC", NDIA 2010 Insensitive Munitions \& Energetic Materials Technology Symposium (IMEMTS) on "International Progress in Insensitive Munitions and Energetic Materials", NDIA Event 1550, Session 9A, Munchen, Germany.

Cerri, S., Bohn, M.A. and Menke, K., 2009, "Ageing Behaviour of HTPB Based Rocket Propellant Formulations", Central European Journal of Energetic Materials, Vol. 6, pp. 149-165.

Badgujar, D.M., Talawar, M.B., Asthana, S.N. and Mahulikar, P.P., 2008, "Advances in science and technology of modern energetic materials: An overview", Journal of Hazardous Materials, Vol. 151, pp. 289-305.

DeLuca, L.T., Galfetti, L., Maggi, F., Colombo, G., Merotto, L, Boiocchi, M., Paravan, C., Reina, A., Tadini, P. and Fanton, L., 2013, "Characterization of HTPB-based solid fuel formulations: Performance, mechanical properties, and pollution", Acta Astronautica, Vol. 92, No. 2, pp. 150-162.

Gascoin, N., Gillard, P., Mangeot, A. and Navarro-Rodriguez, A., 2012, "Literature survey for a first choice of a fuel-oxidiser couple for hybrid propulsion based on kinetic justifications", Journal of Analytical and Applied Pyrolysis, n94, pp. 1-9.

Gomes, S.R., 2012, "Projeto e desenvolvimento de um motor foguete hibrido", Ph.D. Thesis, Instituto Tecnológico de Aeronáutica, Brazil.

Guobiao, C., Hao, Z., Dalin, R. and Hui, T., 2011, "Optimal design of hybrid rocket motor powered vehicle for suborbital flight", Aerospace Sience and Technology, Vol. 25, No. 1, pp. 114-124.
La Fuente, J.L., 2009, "An analysis of the thermal aging behaviour in high-performance energetic composites through the glass transition temperature", Polymer Degradation and Stability, Vol. 94, pp. 664-669

LPI n 9279, de 14/05/1996, Lei da Propriedade Industrial.

Ministério da Defesa, Portaria Normativa $n^{\circ}$ 1888/MD, de 23 de dezembro de 2010

Miskelly, H.L. Jr., 2004, "Destroying airborne biological and/or chemical agents with solid propellants", US 6748868 B1.

Muller, G., "Roadmapping", Embedded Systems Institute. Disponível em: http://www.gaudisite.nl. Acesso em: nov. 2012.

Naya, T. and Kohga, M., 2013, "Influences of particle size and content of HMX on burning characteristics of HMX-based propellant", Aerospace Science and Technology, Vol. 27, No. 1, pp. 209-215.

Ortiz, L.C., Ortiz, W.A. and Silva, S.L., 2002, "Ferramentas alternativas para monitoramento e mapeamento automatizado do conhecimento", Ciência da Informação, Vol. 31, pp. 66-76.

Paterlini, W.C., Botelho, E.C., Rezende, L.C., Lourenço, V.L. and Rezende, M.C., 2002, "Efeito da concentração do catalisador acetilacetonato ferco na cura de poliuretano a base de polibutadieno liquido hidroxilado (BLH) e diisocianato de isoforona (IPDI)", Quim. Nova, Vol. 25, pp. 221-225.

Petersen, E.L., Seal, S., Stephens, M., Reid, D.L., Carro,R., Sammet, T. and Lepage, A., 2012, "Self-extinguishable solid propellant", US 8114229 B1.

Subhananda Rao, A., Krishna, Y. and Nageswara Rao, B., 2004, "Comparison of fracture models to assess the notched strength of composite/solid propellant tensile specimens", Materials Science and Engineering, Vol. A 385, pp. 429-439. 